\title{
Fisiología respiratoria: flujo nasal, hiposmia y SARS-CoV-2
}

\section{Respiratory physiology: nasal flow, hyposmia and SARS-CoV-2}

\author{
Esteban Vergara-de la Rosa, ${ }^{*, \text {, }}$, José Gálvez-Olortegui*,\$, \\ *Scientia Clinical and Epidemiological Research Institute; ”Hospital Regional Docente de Trujillo. Universidad Nacional de Trujillo, \\ Trujillo, Perú; \$Magíster en Investigación Clínica; "Hospital Universitario Central de Asturias, Oviedo, España.
}

\section{Sr. Editor}

Hemos leído con atención el artículo La fisiología clínica en la práctica de la medicina respiratoria. ${ }^{1}$ El autor resalta la importancia del estudio de la fisiología clínica para el adecuado ejercicio de la medicina respiratoria; sin embargo, menciona que su enseñanza ha sido relegada, considerándose de poca relevancia para los médicos en formación. Ante lo anterior, y dada la necesidad de la comprensión de los fenómenos biofísicos de la fisiología de la respiración nasal y los facilitadores de la hiposmia, síntoma sugerente de la COVID-19, intentamos analizar y proponer la participación del tipo de flujo nasal en la generación de la insuficiencia olfatoria, dentro de la interrelación entre las vías aéreas superior e inferior.

La fosa nasal comprende dos regiones bien definidas: la respiratoria, más amplia, y el área olfatoria, superficie estrecha y neural. La hiposmia está relacionada con la afectación neural periférica de la mucosa olfativa ${ }^{2}$ y probablemente su fisiopatología se basa en dos mecanismos. Primero, el epitelio de esa zona de la nariz se infecta debido a la presencia de receptores celulares de la enzima convertidora de angiotensina 2 (ACE2-R), ${ }^{3}$ produciendo edema local; sin embargo, dichos receptores están ausentes en las neuronas olfativas, ${ }^{4}$ lo que propone la existencia de otro factor adicional, facilitador de la baja olfativa. En segundo lugar, a diferencia del área respiratoria, que revela un flujo laminar, el área olfativa lo presenta principalmente de tipo turbulen-

Correspondencia:

Esteban Vergara-de la Rosa

Correo electrónico: estebanvergara@scientiaceri.com

Recibido: 14-III-2021; aceptado: 22-IV-2021.

Citar como: Vergara-de la Rosa E, Gálvez-Olortegui J. Fisiología respiratoria: flujo nasal, hiposmia y SARS-CoV-2. Neumol Cir Torax. 2021; 80 (2): 154-155. https://dx.doi.org/10.35366/100998 to. ${ }^{5}$ En este último tipo de flujo nasal, la presión que ejerce el flujo aéreo sobre la mucosa olfativa es mayor e incrementa el tiempo de exposición de los viriones presentes en la circulación aérea sobre el área olfatoria. Estas propiedades podrían contribuir a la hiposmia y a su inicio temprano y severo, en comparación con otros síntomas respiratorios. ${ }^{6}$

$\mathrm{Si}$ las neuronas del olfato no tienen ACE2-R y la superficie olfativa exhibe un flujo turbulento en la nariz, ${ }^{1}$ surge la pregunta: ¿El flujo turbulento nasal en el área olfatoria contribuye a la hiposmia por SARS-CoV-2?

Una hipótesis a favor es que las anomalías de vías respiratorias superior e inferior, como rinitis alérgica o asma, comorbilidades frecuentes en personas infectadas con ese virus, podrían conducir a mayores tasas de infección e hiposmia, ${ }^{4}$ a causa de la presencia de una alteración de la efusión nasal. Propuestas que apoyan, ahora dentro del marco de la COVID-19, la vigencia del concepto de «una vía aérea única», donde existirían procesos todavía no conocidos que afectarían a toda la ruta aérea.

Asimismo, los ancianos presentan una menor resistencia a la secreción de la nariz, generando un flujo turbulento y una disminución de la velocidad del aire inspirado, facilitando mayores tasas de hiposmia. Por el contrario, los niños manifiestan un flujo principalmente laminar, ${ }^{5}$ que los protegería de dicha afección. Todo lo anterior refuerza la necesidad de considerar a los afectados con comorbilidades respiratorias como aquellos que obligatoriamente necesitarían el enmascaramiento cuidadoso, debido a que actuaría como un efecto de válvula protectora externa.

Finalmente, los pacientes con alteración del flujo nasal por comorbilidad respiratoria podrían tener mayor riesgo de adquirir SARS-CoV-2 y presentar hiposmia. Es necesario desarrollar mayor número de investigaciones relacionadas con la fisiología de la respiración, que correlacionen la influencia de las alteraciones del flujo nasal en patologías de la vía respiratoria inferior. 


\section{REFERENCIAS}

1. Torre-Bouscoulet L. La fisiología clínica en la práctica de la medicina respiratoria. Neumol Cir Torax. 2020;79(4):221-223. Disponible en: https://doi.org/10.35366/97963

2. Gómez-Iglesias P, Porta-Etessam J, Montalvo T, Valls-Carbó A, Gajate V, Matías-Guiu JA, et al. An Online observational study of patients with olfactory and gustory alterations secondary to SARSCoV-2 infection. Front Public Health. 2020;8:243. Available in: https:// doi.org/10.3389/fpubh.2020.00243

3. Li YC, Bai WZ, Hashikawa T. The neuroinvasive potential of SARSCoV-2 may play a role in the respiratory failure of COVID-19 patients. J Med Virol. 2020;92(6):552-555. Available in: https://doi.org/10.1002/ jmv. 25728
4. Brann DH, Tsukahara T, Weinreb C, Lipovsek M, Van den Berge K, Gong B, et al. Non-neuronal expression of SARS-CoV-2 entry genes in the olfactory system suggests mechanisms underlying COVID19-associated anosmia. Sci Adv. 2020;6(31):eabc5801. Available in: https://doi.org/10.1126/sciadv.abc5801

5. Ruiz-Coello AM, Mayayo Al, Pinilla Urraca TM. Fisiología de la nariz y de los senos paranasales. mecanismos de la olfacción. Libro virtual de formación en ORL. 2014. p. 1-15.

6. Lechien JR, Chiesa-Estomba CM, De Siati DR, Horoi M, Le Bon SD, Rodriguez $A$, et al. Olfactory and gustatory dysfunctions as a clinical presentation of mild-to-moderate forms of the coronavirus disease (COVID-19): a multicenter European study. Eur Arch Otorhinolaryngol. 2020;277(8):2251-2261. Available in: https://doi.org/10.1007/s00405020-05965-1 